\title{
Complex automated monitoring of the hydrological and hydrobiological state of basinal freshwater lake Krasilovskoye (Altai Region)
}

\author{
Igor' A. Sutorikhin ${ }^{1}$, Svetlana Yu. Samoilova ${ }^{2}$ \\ ${ }^{1}$ Federal Research Center for Information and Computing Technologies, Novosibirsk, Russia \\ ${ }^{2}$ Institute of Water and Environmental pProblems of the Siberian Branch of the Russian Academy of Sciences, Barnaul, \\ Russia
}

\begin{abstract}
The results of a comprehensive automated monitoring for the hydrological and hydrobiological state of a freshwater Lake Krasilovskoe, conducted since 2013 are given. The experimental dashboard is considered, including the atmospheric-soil measuring complex (ASMC), developed and created in the IMCES SB RAS, Tomsk. An analysis of the dynamics of the lake level during years with contrasting hydrometeorological conditions was performed, which made it possible to identify the main factors that determine the level mode in the spring. In the hydrobiological terms, the dynamics of phytoplankton concentration at different depths in different seasons of the year were investigated. The results of processing Sentinel-1, 2 satellite data and data of natural observations on the distribution of chlorophyll "A" in the surface layer of water sections of the lake water area are discussed.
\end{abstract}

\section{Keywords}

Basinal lake, freshwater lake, monitoring, atmospheric and soil measuring complex, snow survey, spectral underwater illumination, phytoplankton, chlorophyll.

\section{Introduction}

In the conditions of the observed climate change, one of the most pressing problems is the sustainable use of water resources. A significant part of modern research on this topic, due to the problem of fresh water deficiency, the repeatability and scope of hazardous hydrological phenomena, is devoted to estimating the variability of the river flow. Meanwhile, certain volumes of fresh water are contained in lakes, not only the largest (Baikal, etc.), but also a much smaller scale. On the territory of the Altai Krai is up to 13 thousand lakes, most of which have an area of not more than $1 \mathrm{~km}^{2}$ and the depth of 2-3 $\mathrm{m}$ [1]. These water bodies are widely used in economic and recreational purposes. Especially it is necessary to allocate their aquatic and biological resources.

Integrated research and prediction of the elements of the hydrological regime, composition, structure and productivity of phytoplankton, underwater illumination of such lake systems are essential tasks in the process of controlling the water use mode. The article presents the results of a comprehensive monitoring on the basinal freshwater lake Krasilovskoye. Studies

SDM-2021: All-Russian conference, August 24-27, 2021, Novosibirsk, Russia

$\bigoplus$ sia@iwep.ru (I. A. Sutorikhin); bastet@iwep.ru (S. Yu. Samoilova)

(c) (1) ๑ 2021 Copyright for this paper by its authors. Use permitted under Creative Commons License Attribution 4.0 International (CC BY 4.0).

$[\mathrm{m}$ 
are made in three directions: integrated hydrometeorological monitoring (atmospheric-soil measuring complex (ASMC), snow-member shooting), study of species diversity, quantitative composition, structure and productivity of phytoplankton, as well as monitoring the change in spectral transparency of lake water with depth in different seasons of the year.

\section{Research object}

Lake Krasalovskoe is located in the south-east of West Siberian plains, in the Kosikhinsky district of the Altai Territory. The absolute height of the terrain is about $220 \mathrm{~m}$, catchment and water surface 46.11 and $0.8 \mathrm{~km}^{2}$, respectively, the length of the lake is $2.4 \mathrm{~km}$, the average width is $0.33 \mathrm{~km}$, the average depth is $2.7 \mathrm{~m}$, the maximum $-6.5 \mathrm{~m}$. The lake feeds on superficial and groundwater. Landscapes are represented by forests with a rich herbal tier, pine bodies on sand dunes, swamps. Currently, a significant part of the catchment is occupied by cultural agrolandscapes [2]. The climate of the Continental Area, according to the weather station the Troitskoye average January temperature is $-16.6{ }^{\circ} \mathrm{C}$, July -+19.21 , the annual precipitation of $569.9 \mathrm{~mm}[3]$.

\section{Research methods and equipment}

\subsection{Atmospheric-soil measuring complex (ASMC)}

The complex is designed for stationary long-term automatic measurements and registration of the main parameters of the atmosphere, soil and snow cover.

The complex was established in 2013 on the northern shore of the lake, on the territory of the base of educational practices of the Altai State University "Lake Krasilovo". Coordinates of the complex 53.188598ON; 84.365905OE.

Observations for hydrometeorological parameters are made in real time with an interval of 15 minutes and include measurements of the intensity of solar radiation, atmospheric pressure, temperature and humidity, the magnitude of the liquid precipitation, the soil temperature from the surface to a depth of $3.2 \mathrm{~m}$, as well as the height of the snow cover, water level in the lake and groundwater.

Complex consists of two blocks - the "coastal block", located directly near the shoreline and the "water block" - on the water area. The "coastal block" includes a hydrostatic meter of water level in the casing $10 \mathrm{~m}$ long based on a digital sensor 26Ps05SMT (accuracy $\pm 1 \%$ in the range of 0.1-1.5 m). Also, it includes air temperature and humidity meters based on digital sensors DS18B20 and HIH-4021-003, respectively, installed on the mast at an altitude of 2 and $4 \mathrm{~m}$ above the ground surface; Soil measuring device at depths $-0 ; 2 ; 5 ; 10 ; 15 ; 20 ; 30 ; 40 ; 60 ; 80,120 ; 160$; 240 and $320 \mathrm{~cm}$ on the fundamentaries DS18B20. In addition, the groundwater level meter at a depth of $3 \mathrm{~m}$ based on the sensor 26Ps05SMT (accuracy of $\pm 1 \%$ ); The atmospheric pressure meter based on the MPL115A1 sensor (accuracy of $\pm 1 \mathrm{kPa}$ in the range of 50-115 kPa); Meter of the amount of liquid precipitation based on a digital Raincollector II sensor (accuracy of $\pm 0.2 \mathrm{~mm}$ ). For solutions of the task of automatic measurement of the height of snow cover with a high spatial resolution, a method for determining the border of air-snow over the temperature 
difference was selected. This height sensor of the snow cover development of IMCES SB RAS has the ability to use a greater number (50-100) of digital thermometers, which allows to increase the resolution and measurement accuracy (accuracy of $\pm 0.05 \mathrm{~m}$ in the range of $0-1.5 \mathrm{~m}$ ) [4].

Comparison of the results of ASMC measurements on the Krasilovskoye lake and weather station Troitskoye, located $30 \mathrm{~km}$ from the research object, showed the following: the temperature correlation coefficient according to ASMC and weather station Troitskoye was 0.98 . For liquid precipitation, the bond was weaker $(r=0.68)$, which is due to the greater spatial heterogeneity of their distribution. The "water block" was established sensors of measurement of temperature and humidity at a height of 1 and $2 \mathrm{~m}$ from the water surface, as well as the water temperature meter from the surface to the bottom with an interval of $0.5 \mathrm{~m}$. Datas from the sensors to the "water block", as well as on By the shore, the block was read by a logger with an interval of 15 minutes. In the period of the ice station, to the departure of the ice in the spring period, "water block" was dismantled. The "coastal block" unit functioned year-round. The "coastal block" of the ASMC complex on Lake Krasilovskoye and "water block" on Figures 1 and 2.

Snow survey is held annually by the employees of IWEP SB RAS since 2015, with the aim of assessing the thickness and density of snow cover. The shooting is carried out in accordance with the generally accepted requirements [7] during the period of maximum snow storage to the start of the snowmelt (end of February). Measuring the height of the snow cover is made using a SP-110 snowstroke rack, density - with the help of the SU-43 weight meter. Three snowy routes reflecting various landscape conditions of the catchment are laid: in the forest and field, and in 2015 and 2018-2019 directly on the water area of the lake. The thickness of the snow cover is measured every $10 \mathrm{~m}$. One route includes $40-60$ points, in each fifth, the density of snow are determined. In the process of the cameral processing, the height of the snow cover, its coefficient of variation and the standard deviation; snow density, total water supply in snow cover and snow accumulation coefficients (snow-beds ratio forest - field).

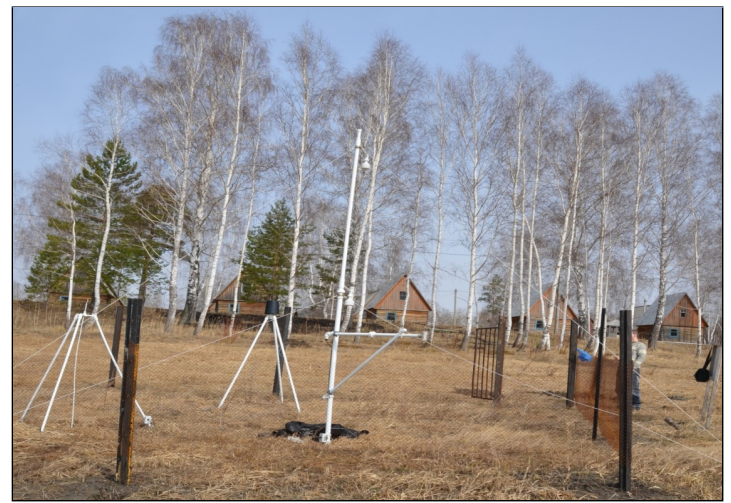

Figure 1: "Coastal block" of the ASMC complex.

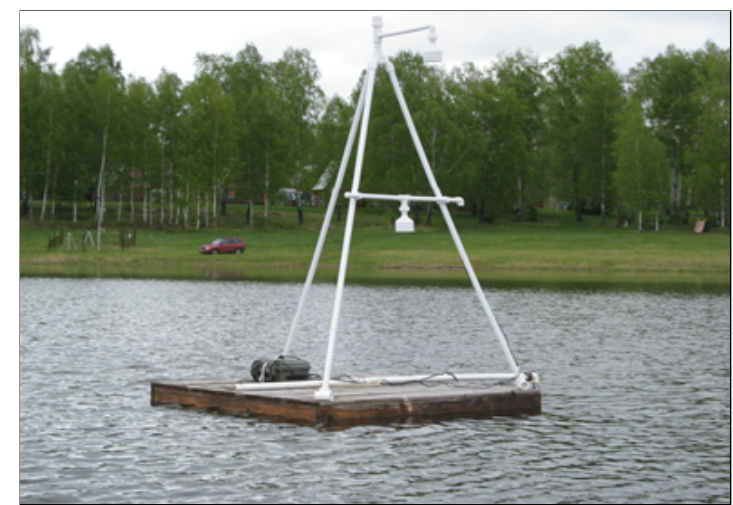

Figure 2: "Water block" of the ASMC complex. 


\subsection{Measurement of the concentration and distribution of chlorophyll " $A$ " in lake Krasilovskoye}

The study of the concentration of chlorophyll "A" is performed on the basis of the analysis of water samples selected both in the surface layer and at different depths of the Krasilovskoye lake in the framework of daily and seasonal field work. For sampling, a 2-liter container used. The concentration of chlorophyll "A" was determined by the standard spectrophotometric method on the extract of fifthoplankton algae pigments [6].

The calculation of the concentration $(\mu \mathrm{g} / \mathrm{l})$ was carried out by the formula:

$$
C=\left(11.85 D_{664}-1.54 D_{647}-0.08 D_{630}\right) \frac{v}{V l},
$$

where $D$ is the optical density of extracts on the corresponding wavelengths; $v$ - volume of extract, $\mathrm{ml} ; V$ - volume of filtered water; $l$ - the length of the optical path in kuvette, sm.

For the preparation of the extract, the water is filtered through the MFAS-OS-3 membrane filter with a pore diameter of $0.08 \mu \mathrm{m}$, chlorophyll pigments are extracted with acetone aqueous solution, centrifuged. The error of determining the concentration of chlorophyll is not more than $10 \%$ [7].

Since, the data of the expeditionary studies gave information only about the local distribution of the chlorophyll content in the selection of water sampling, to assess the spatial distribution of chlorophyll "A" of the surface layer of water in May, July and September 2019, comprehensive experiments were carried out on Lake Krasilovskoye. The determination of the content of chlorophyll "A" in the surface layer of water [8], which included the selection of water sampling coincident in time with the passage of Sentinel-2 satellite in orbit over this water object.

Satellite multispectral data made it possible to obtain an area assessment of the distribution of the concentration of chlorophyll "A" in the surface layer of the reservoir. This work can be divided into the following steps:

1) atmospheric correction;

2) calculation of the NDCI spectral index;

3) calculation of the concentration of chlorophyll content " $\mathrm{A}$ " in the surface layer of water;

4) geographic binding and exports obtained results in the GEOTIFF format.

The implementation of this procedure is based on the components of the ACOLITE computing package, which consists of a set of software modules that implement different algorithms for estimating chlorophyll content "A". On this basis, an independent module of the geographic information system for monitoring the parameters of intra-projectal water objects was developed. Its work can be divided into the following steps. Calculation of the NDCI spectral index (Normalized Difference), which takes into account differences in the reflection in infrared and green areas of the electromagnetic spectrum. The NDCI index allows with relatively small temporary and computational resources to estimate the state of the surface layer of water bodies, this procedure is simple in technological, software implementation. In the course of experiments, the CHL_O2 module, which implements the algorithm for the relationship of the blue and green spectral channels was used [9].

The results of the processing developed by the algorithm, primary information from Sentinel-2 satellites for the selected lake Krasilovskoye during the complex experiment gave a good 
correspondence with full-scale expedition measurements of the chlorophyll concentration in the surface layer of water. Some divergence between satellite measurement data and expedition results can be due to the features of the hydrooptical structure of the surface of the water objects and the abundant effect of atmospheric correction during satellite data processing.

\section{Results and discussion}

\subsection{Dynamics of hydrometeorological parameters and level regime of lake Krasilovskoye}

Analyzed the data of the ASMC complex and snow metering filming, reflecting the processes of snow accumulation, snowmelt, and the level mode of the lake for 4 years (similar to the hydrological ages): 2013-2014, 2014-2015, 2015-2016 and 2016-2017. Part of the materials is presented in the works $[10,11]$. The characteristics of the hydrometeorological parameters that determine the spring lift of the lake level are presented in Table 1.

The maximum spring rise (more than $1.5 \mathrm{~m}$ ) was observed in the spring of 2014, somewhat smaller $-1 \mathrm{~m}-$ in 2016 (Table 1). The main factor determined the significant rise in the level

Table 1

Hydrometeorological parameters and water level rising in 2013-2017.

\begin{tabular}{|c|c|c|c|c|c|c|c|}
\hline \multirow[b]{2}{*}{ Index } & \multicolumn{7}{|c|}{ Period of observation } \\
\hline & $\begin{array}{c}01.10 .2013- \\
10.05 .2014\end{array}$ & \multicolumn{2}{|c|}{$\begin{array}{c}01.10 .2014- \\
10.05 .2015\end{array}$} & \multicolumn{2}{|c|}{$\begin{array}{c}01.10 .2015- \\
10.05 .2016\end{array}$} & \multicolumn{2}{|c|}{$\begin{array}{c}01.10 .2016- \\
10.05 .2017\end{array}$} \\
\hline $\begin{array}{l}\text { Indication of liquid precipitation } \\
\text { for the period of establishing snow } \\
\text { cover (October-November), mm }\end{array}$ & 125.4 & \multicolumn{2}{|c|}{167.4} & \multicolumn{2}{|c|}{81} & \multicolumn{2}{|c|}{109.8} \\
\hline $\begin{array}{l}\text { Terms of establishing sustainable } \\
\text { snow cover according to ASMC }\end{array}$ & 22.12 & \multicolumn{2}{|c|}{26.10} & \multicolumn{2}{|c|}{31.10} & \multicolumn{2}{|c|}{13.10} \\
\hline $\begin{array}{l}\text { Maximum height of snow cover, } \\
\text { according to ASMC, } \mathrm{mm}\end{array}$ & 780 & \multicolumn{2}{|c|}{986} & \multicolumn{2}{|c|}{705} & \multicolumn{2}{|c|}{763} \\
\hline \multicolumn{8}{|l|}{ The average height of the snow } \\
\hline $\begin{array}{l}\text { cover, according to snow member } \\
\text { filming, } \mathrm{mm}\end{array}$ & & $\begin{array}{l}\text { Field } \\
700\end{array}$ & $\begin{array}{c}\text { Forest } \\
950\end{array}$ & $\begin{array}{c}\text { Field } \\
530\end{array}$ & $\begin{array}{l}\text { Forest } \\
750\end{array}$ & $\begin{array}{c}\text { Field } \\
690\end{array}$ & $\begin{array}{c}\text { Forest } \\
1100\end{array}$ \\
\hline Water supply in snow cover, mm & & 213 & 285 & 170 & 203 & 214 & 330 \\
\hline Period of intense snowmelt & $\begin{array}{l}12.03-30.03 \\
(19 \text { days })\end{array}$ & \multicolumn{2}{|c|}{$\begin{array}{l}6.04-14.04 \\
(9 \text { days })\end{array}$} & \multicolumn{2}{|c|}{$\begin{array}{l}23.03-08.04 \\
(16 \text { days })\end{array}$} & \multicolumn{2}{|c|}{$\begin{array}{l}25.03-12.04 \\
(19 \text { days })\end{array}$} \\
\hline $\begin{array}{l}\text { The average temperature of the } \\
\text { air during the period of intense } \\
\text { snowmelt, }{ }^{\circ} \mathrm{C}\end{array}$ & 1.6 & \multicolumn{2}{|c|}{4.1} & \multicolumn{2}{|c|}{2.7} & \multicolumn{2}{|c|}{1.4} \\
\hline $\begin{array}{l}\text { The amount of liquid precipitation } \\
\text { for the period of the snowmelt, } \\
\mathrm{mm}\end{array}$ & 0 & \multicolumn{2}{|c|}{41.6} & \multicolumn{2}{|c|}{14} & \multicolumn{2}{|c|}{14.6} \\
\hline The beginning of the spring rise & 20.03 & \multicolumn{2}{|c|}{20.04} & \multicolumn{2}{|c|}{30.03} & \multicolumn{2}{|c|}{10.04} \\
\hline $\begin{array}{l}\text { The magnitude of the spring lift- } \\
\text { ing level, } \mathrm{mm}\end{array}$ & 1540 & \multicolumn{2}{|c|}{630} & \multicolumn{2}{|c|}{1000} & \multicolumn{2}{|c|}{400} \\
\hline
\end{tabular}


of the soil in winter 2013-2014 and 2015-2016 was the establishment of snow cover after the onset of significant (below $10^{\circ} \mathrm{C}$ ) of frosts, as well as the formation on the surface of the Ice "locking" layer during the winter thaws (Figure 3).

On the contrary, the conditions for the formation of snow cover in the winter of 2014-2015 and 2016-2017 did not contribute to the freezing of the soil (Figure 3). Due to the intensive infiltration of melt water into the underlying layers of the soil, the height of the rise of the water level in the lake turned out to be significantly lower than -0.6 and $0.4 \mathrm{~m}$, respectively.

The beginning of the lifting of the lake level after the snowmelt and with less intensity during the years without freezing (2015 and 2017) indicates that the spring inflow of water in the lake was carried out mainly due to the underground flow. On the contrary, the rapid rise in the level of the lake in the years with a freezing indicates an increase in the proportion of the surface drain.
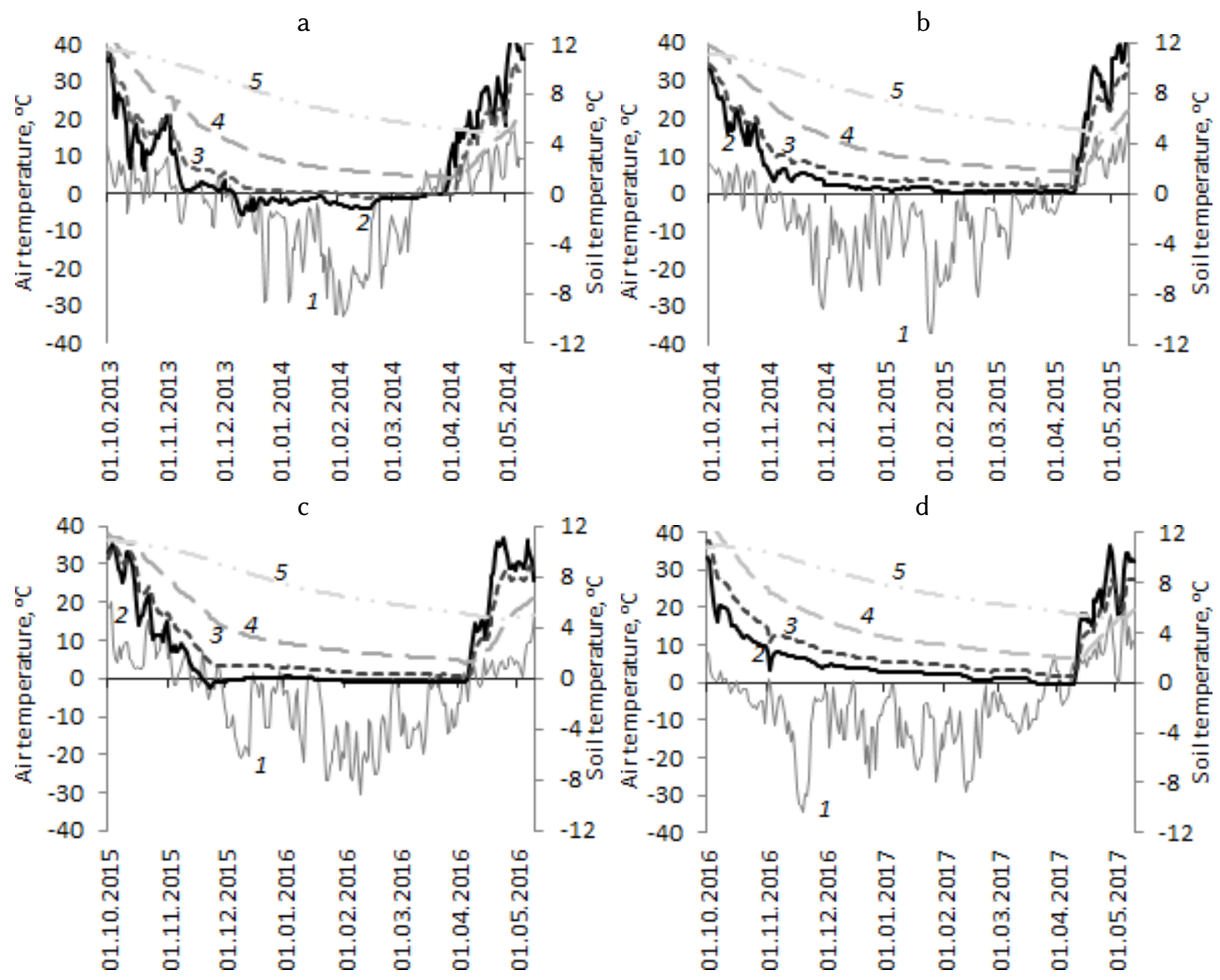

Figure 3: The average daily air temperatures at an altitude of $2 \mathrm{~m}$ (1) and soil at a depth of 5 (2), 30 (3), 120 (4) and 320 (5) cm according to ASMC data in 2013-2014 (a), 2014-2015 (b), 2015-16 (c) and 2016-2017 (d). 


\subsection{Distribution of chlorophyll " $A$ " in depth and in the surface layer of water lake Krasilovskoye}

One of the most important indicators in assessing the ecological state of the pond is its trophic status, which is determined primarily by the magnitude of the primary products and the content of chlorophyll " $\mathrm{A}$ " in the water. In assessing the trophic status, classical approaches are traditionally used such as determination of the concentration of chlorophyll "A", common phosphorus and nitrogen. In the process of monitoring studies, the species composition and structure of phytoplankton was determined lake Krasilovskoye in different seasons of the year. In the course of the research, an unusual result was recorded when in the decorative period in February 2018 there was an intensive development of phytoplankton at depths from 1.5 to 3 meters. As a result, in the spring of this year, there was a death of fish associated with a lack of oxygen occurred after the deployment of ice cover. Figure 4 shows a graph of the concentration of chlorophyll concentration "A" from depth in winter period of different years, which indicates a significant range of changes in this environmental parameter (from 2 to 5 times), due to the course of hydrobiological processes in the lake.

Processed satellite multispectral data in conjunction with the results of expeditionary work on the lake made it possible to construct schemes the distribution of chlorophyll "A" in the

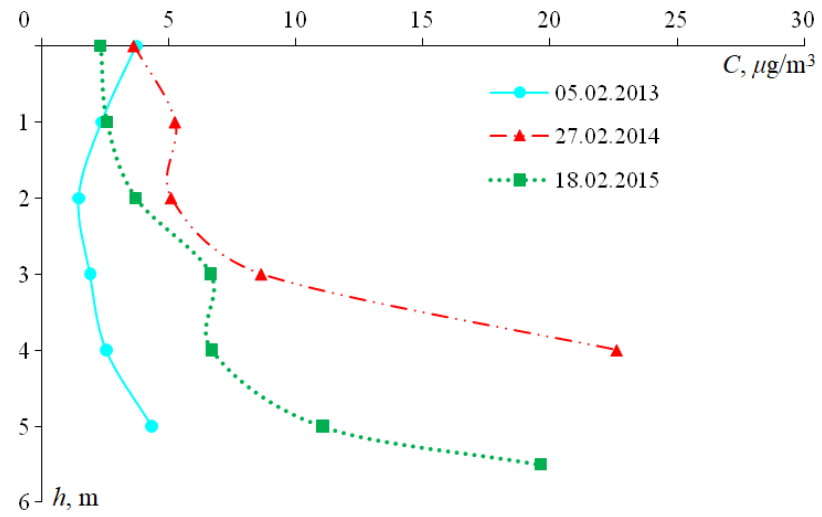

Figure 4: Changes in the concentration of chlorophyll "A" from depth in the winter period of different years on lake Krasilovskoye.

a

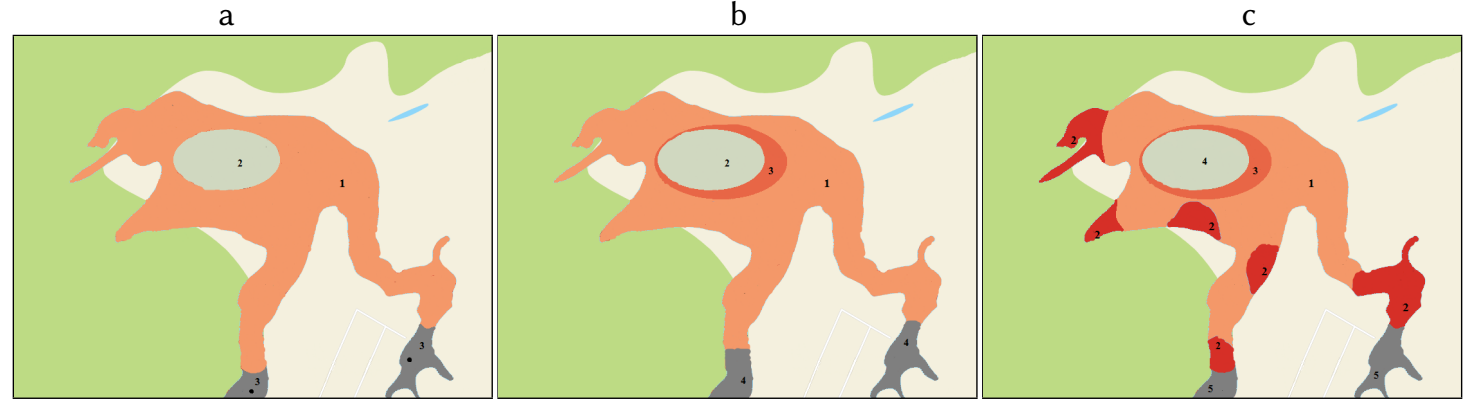

Figure 5: Distribution of chlorophyll "A" in the surface layer of lake Krasilovskoe on 18.05.2019 (a), 24.08.2019 (b) and 27.09.2019 (c) according to the results of ground and satellite measurements. 


\section{Table 2}

Concentration of chlorophyll "A" in the surface layer of Lake Krasalovskoe on expeditionary and satellite data in May, June and September 2019.

\begin{tabular}{ccc}
\hline Zone & Expeditionary measurements, $\mathrm{mg} / \mathrm{m}^{3}$ & Sentinel-2, $\mathrm{mg} / \mathrm{m}^{3}$ \\
\hline \multicolumn{3}{c}{18.05 .2019} \\
2 & 1.9 & 2.2 \\
3 & 1.4 & 1.6 \\
& 2.8 & 3.2 \\
\hline 1 & 24.08 .2019 & \\
2 & 14.3 & 14.5 \\
3 & 8.2 & 6.7 \\
4 & 10.7 & 11.0 \\
& 16.4 & 18.1 \\
\hline 1 & 27.09 .2019 & 19.2 \\
2 & 18.5 & 21.8 \\
3 & 21.6 & 14.7 \\
4 & 14.7 & 11.1 \\
5 & 10.4 & 28.7 \\
\hline
\end{tabular}

surface layer of water sections of the water area in May, June and September 2019 (Figure 5 and Table 2).

The most consistent results are consistent with satellite measurement data, which confirms the correctness of the selected data processing scheme. According to the obtained card schemes, you can quantify the change in the ecological state of the lake in the spring, summer and autumn periods of the year.

\section{Conclusion}

Using the measurement data of the FIC complex and snow metering, it was possible to analyze the hydrometeorological parameters of the catchment of the Krasilovskoye lake, evaluate the spring level mode in different years. The state of soils on the catchment (moisturizing, freezing) is the main factor determining the loss of melting on infiltration and the ratio of surface and underground flow during the snowmelt.

It has been established that the species composition and abundance of summer phytoplankton, the concentration of chlorophyll "A", the nature of the distribution of these parameters in depth corresponds to those in small mesotrophic and ephrophic reservoirs of the moderate zone.

The fact of the intensive development of algae in lake Krasilovskoye is unexpected in a stale period, since so far, such information about the water bodies of the Altai Territory was absent due to difficulties in the winter and prejudice, which is a sleda period in the life of the fortune bodies. 
Allegedly, according to the morphological features and content of chlorophyll "A", even in conditions of insufficient lighting at the bottom of the summer or in a sleda period in the entire thickness of water, green, eurlen, dinofite, cryptophyte, ocher-breeding and cyanobacteria are actively photosynthesize.

\section{References}

[1] Encyclopedia of the Altai Territory: in 2 volumes. Barnaul: Picket, 1997. Vol. 1. 366 p.

[2] Baryshnikova O.N., Kharlamova N.F., Kozyreva Yu.V., Nesasheva G.I. The physicogeographical characteristics of the complex educational and scientific hospital Altgu "Lake Krasalovo". Barnaul, 2013. 112 p.

[3] Rp5.ru reliable prognosis. Available at: http://rp5.ru.

[4] Dukarev E.A., Kurakov S.A., Ushakov V.G., Kiselev M.V., Makeev E.A. Supporting automatic temperature meters to study the characteristics of snow cover // Materials of the IV AllRussian Scientific and Practical Conference with International Participation "Modern Problems of Geography and Geology". Tomsk: Publishing House of Tomsk State University. P. 246-248.

[5] Bykov N.I., Popov E.S. Observation for the dynamics of snow cover in the OPT of AltaiSayan Ekoregion (Methodical manual). Krasnoyarsk, 2011. 64 p.

[6] GOST 17.1.4.02-90

[7] Akulova O.B., Bukatoy V.I., Sutorikhin I.A. The influence of natural water components on the spectral indicator of the weakening of light (on the example of the water bodies of the Altai Territory) // Optics of the atmosphere and ocean. 2017. Vol. 30. No. 5. P. 414-419.

[8] Donzov A.A., Sutorikhin I.A., Yermakov M.G., Ermakov Y.G. Geoinformation Web - A system for collecting and processing data on the status of lakes and reservoirs // Polzunovsky Almanac. 2020. No. 4. P. 98-104.

[9] Acolite. Available at: http://www.odnature.naturalsciences.be.

[10] Zuev V.V., Zueva N.E., Kurakov S.A., Sutorikhin I.A., Kharlamova N.F. The dynamics of the spring lift of the standard lakes (on the example of the Lake Krasilovskoye Altai Territory) // Geography and Natural Resources. 2016. No. 4. P. 76-80.

[11] Sutorikhin I.A., Samoilova S.Yu., Kolomeichev A.A., Kurakov S.A. The dynamics of the hydrometeorological conditions and the parameters of the snow cover in the basin of the Fleet Lake Krasilovskoye (Altai Territory) in 2013-2017 // Izvestia JSC RGO. 2020. No. 2(57). P. 64-74. 